Available online at http://jddtonline.info

RESEARCH ARTICLE

\title{
FORMULATION OF SUSTAINED RELEASE CHLORPHENIRAMINE MALEATE MATRIX TABLETS THROUGH OPTIMIZATION AND THEIR EVALUATION
}

\author{
Masheer Ahmed Khan* \\ School of Pharmacy, Devi Ahilya Vishwavidyalaya, Takshshila Campus, Khandwa Road, Indore-452001, India \\ *Corresponding Author's Telephone: +91-9425069821, E-mail: masheerak@yahoo.com
}

Received 10 August 2012; Review Completed 19 Aug 2012; Accepted 03 Sep 2012, Available online 15 Sep 2012

\begin{abstract}
The object of the present study is to develop sustained release system of the antihistaminic agent chlorpheniramine maleate generally used in allergic disorders common cold and other conditions. Matrix tablet is one of the least complicated devices to sustain the release of drug candidates. Different grades of polymers HPMC viz HPMCK4M and HPMCK15M were selected to sustain the release up to $12 \mathrm{hrs}$. Optimization techniques using factorial design for two factors at three levels $\left(3^{2}\right)$ was selected to optimize varied response variables viz. release rate exponent (n), t50\%, $\mathrm{k}$, amount of drug released in $12 \mathrm{~h}$ (Rel12h) and mean dissolution time MDT. The optimum formulations were selected and the results obtained with the experimental values were compared with the predicted values. In conclusion, the results suggest that the developed sustained-release matrix tablets could provide quite regulated release of chlorpheniramine maleate up to nearly $12 \mathrm{hr}$.

Key words: chlorpheniramine maleate, Matrix tablets, Sustained release, HPMC, Polymer, Factorial design
\end{abstract}

\section{INTRODUCTION}

A computer optimization technique, based on responsesurface methodology has proven to be a useful approach for selecting pharmaceutical formulations. Factorial designs are the most popular response surface designs ${ }^{1-2}$. A factorial design for two factors at three levels $\left(3^{2}\right)$ which is equivalent to a central composite design (CCD) for two factors was selected to optimize varied response variables viz. release rate exponent (n), t50\%, k, amount of drug released in $12 \mathrm{~h}$ (Rel12h) and mean dissolution time MDT ${ }^{3-}$ 5 .

Chlorphenirame maleate is an alkylamine derivative with the properties and uses of the antihistamines and generally causes less sedation. It antagonizes actions of histamine at the $\mathrm{H} 1$ receptors. Doses - Usually 4mg, 3-4 times daily, higher doses up to $36 \mathrm{mg}$ daily, in sustained release preparations are given. It is used in conditions like Allergic Disorders, Renal failure ,Common Cold and others ${ }^{6,7}$.

Matrix tablet is the least complicated approach in devising a sustained release dosage form and involves the direct compression of blend of drug, retardant material, and additives to form a tablet in which the drug is embedded in a matrix core of the retardant. Hydrophilic matrices are well mixed composite of one or more drugs with a hydrophilic polymer. Hydrophilic matrices possesses major advantages over other alternatives in developing oral controlled release drug delivery as they have a capacity to incorporate large doses of drugs, these can't be disintegrated throughout the GI tract so the dose dumping is not there ${ }^{8-12}$.

In the current study different grades of HPMC like K4M, $\mathrm{K} 15 \mathrm{M}$ and $\mathrm{K} 100 \mathrm{M}$ were selected during preliminary studies for regulating the release of the drug chlorphenirame maleate. Two polymers HPMCK4M and HPMCK15M were further selected for optimization studies 13-15.
Sustained release of drug is required to reduce the frequency of administration. Therefore the object of present study is to enable a simpler method of manufacture of tablets to provide sustained release of the drug content up to $12 \mathrm{hrs}$.

\section{MATERIALS UNDER METHODS}

Chlorphenirame maleate was obtained as a gift sample from Promed Labs. Ltd, Indore, (M.P.), HPMC(K4M, K15M, K100M) were provided by Colorcon India Ltd., Goa, dicalcium phosphate, microcrystalline cellulose (Avicel PH101), purified talc, magnesium stearate and all other reagent used were of analytical grade.

\section{Pre-optimization studies}

Nine formulations employed for pre-optimization investigations containing different ratios of HPMCK4M, HPMCK15M and HPMCK100M, keeping the total tablet weight constant at $120 \mathrm{mg}$. The tablets were prepared by direct compression. The values of response variables viz. $n$, rel12h, MDT, t50\%, t70\% and $\mathrm{t} 80 \%$ were studied to help in choosing the best possible combination for further optimization studies.

\section{Factorial Design}

The $3^{2}$ factorial designs were selected using two factors (polymers) at three levels and the factor levels were suitably coded. Nine formulations were prepared as per the design and coded F1-F9. The two polymers HPMC K4M and HPMC K15M were selected and their limits were chosen for subsequent detail studies using the factorial design. The amount of drug, magnesium stearate, MCC and talc were kept constant while dicalcium phosphate was taken in sufficient quantity to maintain a constant tablet weight of $120 \mathrm{mg}$. The translation of the coded factor level as amount of ingredients is listed in Table (1). 
Table 1: Translation of experimental conditions into physical units

\begin{tabular}{|c|c|c|c|c|}
\hline Coded Factor & Level & Factor(X1) & Factor (X2) & \multirow{2}{*}{ Units } \\
\cline { 3 - 4 } & & HPMC K4 & HPMC K $\mathbf{K}_{\mathbf{1 5}} \mathbf{M}$ & \\
\hline-1 & Low & 25 & 15 & $\mathrm{mg}$ \\
0 & Intermediate & 35 & 22.5 & $\mathrm{mg}$ \\
1 & High & 45 & 30 & $\mathrm{mg}$ \\
\hline
\end{tabular}

\section{Preparation of Tablets and Physical Evaluation}

Tablet batches consisting of 100 tablets were prepared by direct compression method. All the product and process variables other than the concentration of two polymers were kept constant. The composition of nine formulations F1-F9 as per factorial design during optimization studies are shown in Table (2a.). Ten tablets from each batch were weighed individually and subjected to physical evaluation.

\section{Dissolution Studies}

Dissolution studies were carried out for all the nine formulations in triplicate, employing dissolution USPXXII paddle apparatus, using distilled water $\mathrm{pH} 6.3$ as the dissolution medium at $50 \mathrm{rpm}$ and $37 \pm 0.5^{\circ} \mathrm{C}$. An aliquot of sample was periodically withdrawn at suitable time intervals and volume replaced with equivalent amounts of plain dissolution medium. The samples were analyzed at $261 \mathrm{~nm}$.

\section{Data Analysis}

The raw data obtained from in vitro dissolution was analyzed using the software. The software has in built provisions for calculating the values of amount of drug release, percentage of drug release, log fraction released at various time interval, log time, mid-point of time intervals and rate of drug release ${ }^{16-18}$.

The software also calculates the kinetic constant $(\mathrm{K})$, the diffusional release exponent (n) using logarithmic transformation, coefficient of determination $\left(\mathrm{R}^{2}\right)$, standard error of estimation (SEOE), significance test, ' $\mathrm{t}$ ' values and 'p' valuesare shown in Table (2b). These values are calculated from the interpolation option the graphs. The response variables, which were considered for optimization included, $\mathrm{n}$, mean dissolution time (MDT), release at $12^{\text {th }}$ $\mathrm{hr}\left(\mathrm{rel}_{12} \mathrm{~h}\right), \mathrm{t} 50 \%$ were also calculated. Finally, the prognosis of optimum formulation was conducted in two stages. First, a feasible space was located and second, an exhaustive grid search was conducted to predict the possible solutions. The optimum formulation were selected by the critical evaluation of the tabulated grid search values

\section{Preparation of Predicted optimum Formulation}

The tablet formulations were compressed using the chosen optimal composition and evaluated for physical test, tablet assay and dissolution performance. The observed and predicted responses were critically compared.

Table 2a: Composition of different formulations used as per factorial design during optimization studies

\begin{tabular}{|c|c|c|c|c|}
\hline Formulation Code & HPMCK4M & HPMCK15M & Total Polymer Content & Units \\
\hline F1 & 25 & 15 & 40 & $\mathrm{mg}$ \\
\hline F2 & 25 & 22.5 & 47.5 & $\mathrm{mg}$ \\
\hline F3 & 25 & 30 & 55 & $\mathrm{mg}$ \\
\hline F4 & 35 & 15 & 50 & $\mathrm{mg}$ \\
\hline F5 & 35 & 22.5 & 57.5 & $\mathrm{~m}$ \\
\hline F6 & 35 & 30 & 65 & $\mathrm{mg}$ \\
\hline F7 & 45 & 15 & 60 & $\mathrm{mg}$ \\
\hline F9 & 45 & 22.5 & 75 & $\mathrm{mg}$ \\
\hline
\end{tabular}

\section{RESULTS}

\section{Pre-optimization Studies Results}

The data obtained during the pre-optimization studies reveals that as the molecular weight or the viscosity of the polymer increases, release rate of the drug from the formulation decreases. These studies help in the selection of the appropriate range of polymer for the further optimization studies.

\section{Physical Evaluation and Assay of Tablet}

The tablet weights of all the nine batches vary between 120 and $121 \mathrm{mg}$, diameter around $7.22 \mathrm{~mm}$, thickness between $2.11 \mathrm{~mm}$ to $2.14 \mathrm{~mm}$ and tablet hardness between 5.5 to 5.9 $\mathrm{Kg}$. The assay was performed taking 20 tablets weighed and powdered equivalent to about $4 \mathrm{mg}$ of chlorphenirame maleate shaken with $20 \mathrm{ml}$ of $0.05 \mathrm{M}$ sulphuric acid for 5 minutes then added $20 \mathrm{ml}$ of ether and filtered the acid layer. The ether layer was extracted with two quantities each of $10 \mathrm{ml}$ of $0.05 \mathrm{M}$ sulphuric acid. The combined acid extracts were made alkaline to litmus paper with $1 \mathrm{M}$ sodium hydroxide and extracted with two quantities each of $50 \mathrm{ml}$ of ether. Each ether extract was washed with the water and $0.25 \mathrm{M}$ sulphuric acid, diluted and measured the absorbance of the resulting solution at about $265 \mathrm{~nm}$. The assay values varied between $95.83 \%$ to $98.75 \%$. The tablet friability ranged between 0.5 to $0.8 \%$. The physical parameters of the manually compressed tablets were found within control. 
Khan et al

Release Profile Studies

Journal of Drug Delivery \& Therapeutics; 2012, 2(5), 45-49

The dissolution parameters of nine formulations as per design containing HPMCK4M and HPMCK15M polymer combination with different ratios, obtained are shown in the
Table (2). The release pattern between percent drug release vs. time and plot between cumulative percent drug release vs square root of time (Higuchi Plot) are shown in Fig. (1) and Fig. (2), respectively.

Table 2b: Dissolution parameters of (HPMCK4M - HPMCK15M) polymer combinations with different ratios during optimization studies using $3^{2}$ factorial design.

\begin{tabular}{|c|c|c|c|c|c|c|c|c|c|c|c|}
\hline $\begin{array}{c}\text { Formulation } \\
\text { Code }\end{array}$ & $\mathbf{n}$ & $\mathbf{k}$ & MDT & Rel 12 hr & Rel 24 hr & t $50 \%$ & $\begin{array}{c}t \\
60 \%\end{array}$ & t $70 \%$ & $\begin{array}{c}\mathbf{t} \\
80 \%\end{array}$ & $\mathbf{T}$ & $p$ value \\
\hline F1 & 0.547 & 0.3053 & 3.0938 & 102.73 & N.C.* & 2.5 & 2.916 & 3.5 & 4.666 & 12.422 & $<0.0005$ \\
\hline $\mathrm{F} 2$ & 0.5087 & 0.2884 & 3.8851 & 93.0511 & N.C.* & 2.8125 & 3.368 & 3.894 & 5 & 12.434 & $<0.0005$ \\
\hline F3 & 0.5046 & 0.249 & 5.2737 & 89.6962 & N.C.* & 3.666 & 5.125 & 6.545 & 8.57 & 18.954 & $<0.0005$ \\
\hline $\mathrm{F} 4$ & 0.5094 & 0.2486 & 5.1873 & 91.1045 & N.C.* & 4 & 5.333 & 6.571 & 9.25 & 15.725 & 0.0005 \\
\hline F5 & 0.4809 & 0.2459 & 6.0035 & 87.983 & N.C.* & 4.375 & 5.714 & 7.6 & 10 & 16.160 & $<0.0005$ \\
\hline F6 & 0.4537 & 0.2541 & 6.3933 & 84.2741 & 101.352 & 4.5 & 5.166 & 7.25 & 11 & 16.206 & $<0.0005$ \\
\hline F7 & 0.4597 & 0.257 & 6.0507 & 85.999 & 102.077 & 4.458 & 4.875 & 5.875 & 9.71 & 13.50 & $<0.0005$ \\
\hline F8 & 0.4443 & 0.235 & 8.009 & 74.996 & 84.8205 & 5.214 & 5.928 & 9.333 & 17.33 & 15.481 & $<0.0005$ \\
\hline F9 & 0.4182 & 0.2565 & 7.632 & 74.0834 & 93.9749 & 5.444 & 7.25 & 10.666 & 15.42 & 40.524 & $<0.0005$ \\
\hline
\end{tabular}

N.C. - Not calculated

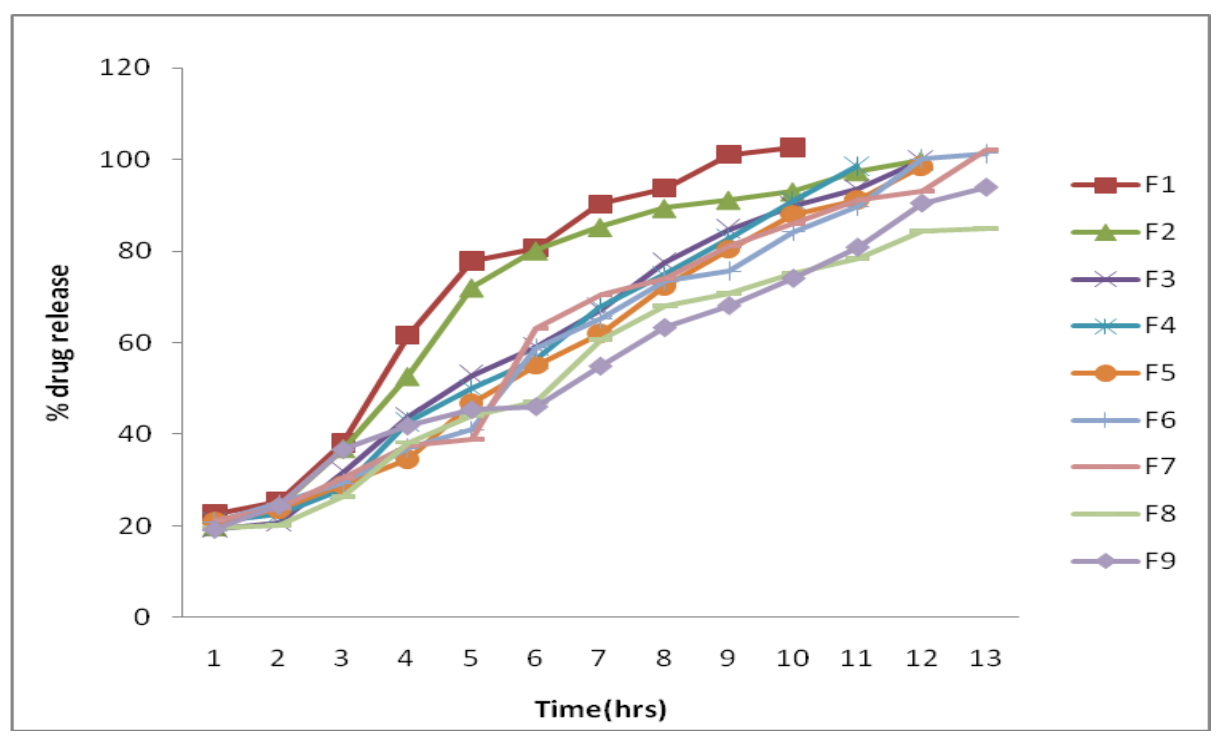

Figure 1: Plot between percent drug release and time for formulations as per Factorial design

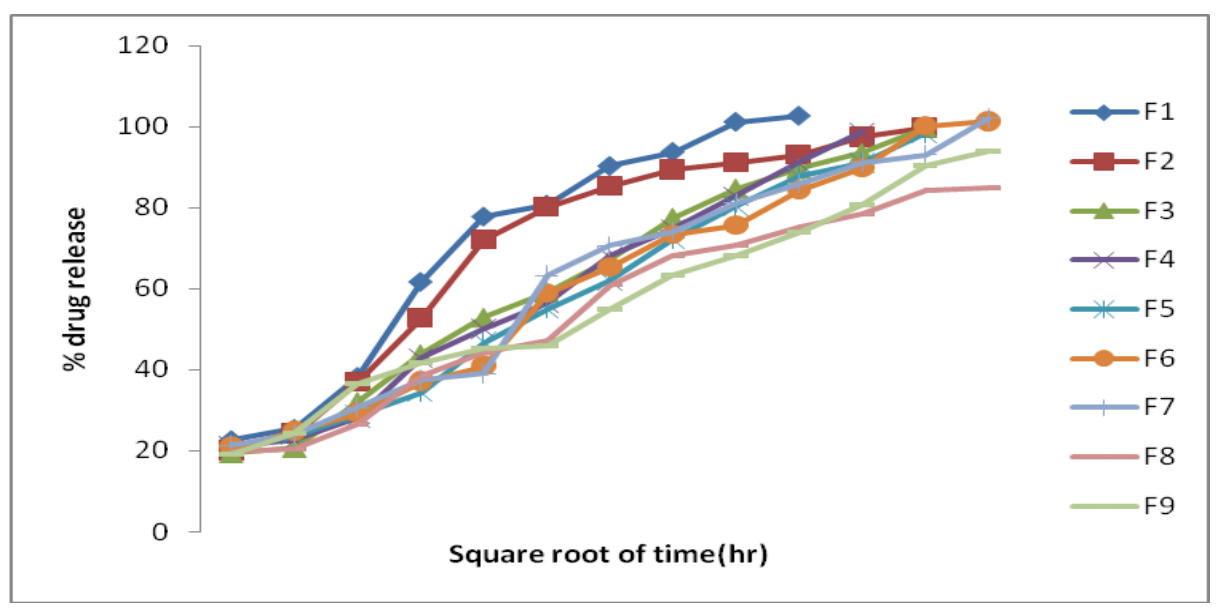

Figure 2: Plot between cummulative percent drug release and square root of time (Higuchi).

\section{Response Surface Analysis -Calculation of Coefficient}

The coefficients of the polynomial equations for responses $\mathrm{n}, \mathrm{k}$, Rel $12 \mathrm{hr}$, MDT and $\mathrm{t} 50 \%$ are listed Table (3) along with their values of $R^{2}$. Coefficients $\left(B_{1}-B_{5}\right)$ were calculated with $\mathrm{B}_{0}$ as the intercept using the polynomial equation

$$
\begin{gathered}
\mathrm{Y}=\mathrm{B} 0+\mathrm{B} 1 \mathrm{X} 1+\mathrm{B} 2 \mathrm{X} 2+\mathrm{B} 3 \mathrm{X} 1^{2}+\mathrm{B} 4 \mathrm{X} 2^{2}+\mathrm{B} 5 \mathrm{X} 1 \mathrm{X} 2+ \\
\mathrm{B} 6 \mathrm{X} 1 \mathrm{X} 2^{2}+\mathrm{B} 7 \mathrm{X} 1^{2} \mathrm{X} 2+\mathrm{B} 8 \mathrm{X} 1^{2} \mathrm{X} 2^{2}
\end{gathered}
$$


The coefficient of the above equation was calculated by regression using the transformed data taken for Factor $\mathrm{X} 1(\mathrm{HPMCK} 4 \mathrm{M})$ and Factor X2 (HPMCK15M) as shown in Table(1).
The value of $\mathrm{R}^{2}$ is quite high for Rel12h, t50\%, $\mathrm{n}$ and MDT so for these responses, the polynomial equations form excellent fits to all the experimental data and statistically valid Table (3).

Table 3: Values of the coefficient for the polynomial equations and $\mathrm{R}^{2}$ for various response variables of the formulations

\begin{tabular}{|c|c|c|c|c|}
\hline Coefficient & $\mathrm{n}$ & MDT & Rel 12th Hr. & $\mathrm{t} 50$ \\
\hline B0 & 0.481 & 5.725 & 87.102 & 4.108 \\
\hline B1 & -0.040 & 1.573 & -8.400 & 1.023 \\
\hline B2 & -0.023 & 0.828 & -5.297 & 0.442 \\
\hline B3 & 0.000 & -0.150 & 0.279 & -0.045 \\
\hline B4 & -0.001 & -0.204 & -1.028 & -0.276 \\
\hline B5 & 0.004 & -0.361 & 2.638 & -0.039 \\
\hline B6 & -0.011 & -0.733 & 0.942 & -0.267 \\
\hline B7 & 0.007 & 0.337 & -2.822 & 0.288 \\
\hline B8 & 0.005 & -0.221 & 4.397 & 0.129 \\
\hline R & 0.999845 & 1.000000 & 1.000000 & 1.000000 \\
\hline
\end{tabular}

\section{Search for Optimum Formulations}

The criterion for selection of suitable feasible region was primarily based on highest possible values of $\mathrm{n}$, Rel $12 \mathrm{hr}$, MDT and $50 \%$. Two regions were selected on the basis of Region 1 dissolution parameters obtained during optimization studies of formulations F1-F9. The exel sheet was used to predict and determine the responses between the Region 1 and further Region 2, termed as feasible regions for factorX1 and FactorX2 (HPMCK4M and HPMCK15M).

rel $12 \mathrm{hr}>90 \% ; \mathrm{n}>0.460 ;$ MDT $>3.1 ; \mathrm{t} 50 \%>2.5 \mathrm{hr}$.

Region 2

rel $12 \mathrm{hr}>96 ; \mathrm{n}>0.49 ;$ MDT $>3.8 ; \mathrm{t} 50 \%>3 \mathrm{hr}$

The predicted values for the responses were noted and are shown in Table (4a). Based on the predicted values the levels were decoded and factor values were determined (refer Table (1). Values obtained for HPMCK4M were 27.2 mg and HPMCK15M were $18.15 \mathrm{mg}$. using these amounts tablets of optimum formulation was prepared and subjected to dissolution studies. The dissolution parameters obtained for optimum formulation are shown in Table (4b).

Table 4a: Predicted values of optimum formulations

\begin{tabular}{|c|c|c|c|c|c|c|c|}
\hline $\mathrm{n}$ & $\mathrm{k}$ & MDT & Rel12hr & $\mathrm{t} 50$ & $\mathrm{t} 60$ & $\mathrm{t} 70$ & $\mathrm{t} 80$ \\
\hline 0.5218 & 3.720 & 3.8994 & 96.273 & 2.81 & 3.3884 & 3.894 & 4.890 \\
\hline
\end{tabular}

Table 4b: Dissolution parameters of optimum formulation

\begin{tabular}{|c|c|c|c|c|c|c|c|}
\hline $\mathrm{n}$ & $\mathrm{k}$ & MDT & Rel12hr & $\mathrm{t} 50$ & $\mathrm{t} 60$ & $\mathrm{t} 70$ & $\mathrm{t} 80$ \\
\hline 0.5215 & 3.7205 & 3.7144 & 95.54 & 2.80 & 3.3684 & 3.8947 & 4.8889 \\
\hline
\end{tabular}

\section{Comparison of Optimum Formulation}

The results of the physical evaluation and tablet assay of the optimum formulation were within limits. Dissolution parameters like n, MDT, Rel $12 \mathrm{n}$ and $\mathrm{k}$ were tabulated for optimized matrix tablets formulation and shown in Table (4b.). The plot between percent drug release and time of the optimized formulation is shown in Fig. (3).

The comparison of the observed responses with anticipated responses along with percent error are listed in Table (5). The results obtained of the experimental values are very much close to the predicted values for the two responses $\mathrm{n}$ and Rel12hr.

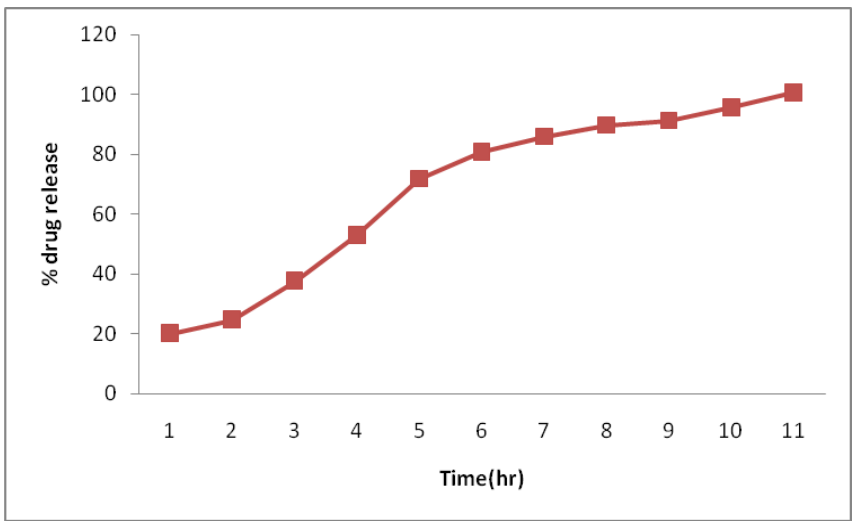

Figure 3: Plot between percent drug release and time of the optimum formulations 
Table 5: Comparison of experimental results with predicted responses

\begin{tabular}{|c|c|c|c|c|}
\hline $\begin{array}{c}\text { Composition HPMCK4M/ } \\
15 \mathrm{M}\end{array}$ & Response & Predicted Value & Experimental Value & Percentage Error \\
\hline \multirow{2}{*}{$27.2 / 18.15$} & $\mathrm{n}$ & 0.5218 & 0.5215 & 0.05 \\
\cline { 2 - 5 } & Rel 12 & 96.2730 & 95.54 & 0.76 \\
\hline
\end{tabular}

\section{DISCUSSION}

The dissolution data indicates that as the content of HPMCK4M and HPMCK15M increased, the value of $n$ was found to decrease, except when HPMCK4M content increased from intermediate to high level. By and large the table delineates a decreasing trend in the value of $n$ as the ratio of total polymer content to drug increased. In general the release pattern tends to approach Fickian release with increase in polymer content.

The values of $\mathrm{k}$ showed however no distinct trend with increase in concentration of polymers. The values of Rel12h showed that with an increasing total polymer content resulted in the decrease in the drug release. The inverse relationship is there between the total polymer content and drug release.

The value of overall rate of release decreases with increasing concentration of HPMCK4M and HPMCK15M from low to intermediate levels. Increasing the concentration to high level of HPMCK4M and HPMCK15M did not have any significant effect or release rate, in accordance with the previous reports, wherein a saturation effect occurred at high concentration. The general pattern was a decrease in release rate with an increase in amount of total polymer content. This is in clear accordance with earlier findings.

The values of MDT showed that with increasing total polymer content resulted in the increase of mean dissolution time. MDT is used to characterize drug release

\section{REFERENCES}

1. Swarbric J, and Boylan J.C.; Encyclopedia of Pharmaceutical Technology, Marcell Dekker, New York, 1995.

2. Bolton S.; Pharmaceutical Statistics: Practical and Clinical Applications. $2^{\text {nd }}$ Ed., Marcel Dekker Inc, New York, 1990, 308-570.

3. Banker G., Rhodes C.; Modern Pharmaceutics, Marcel Dekker, New York, 1996, 247-289

4. Lewis GA, Mathieu D. and Phan-Tan-Luu R.; Pharmaceutical Experiment Design (Drugs and Pharmaceutical Sciences), Marcel Dekker, Inc., New York, 1999.

5. Box G., Connor C., Cousins W., Davies O, Himsworth F and Sillito G.; The Design and Analysis of Industrial Experiments Davies, O.L., (Ed) $2^{\text {nd }}$ edition, Oliver and Boyd, London, 1960,495-565.

6. Mickey.LW and Eugene LP, Effect of anionic surfactants on the release of chlorpheniramine maleate from an inert heterogenous matrix, Drug development and Industrial Pharmacy, 18(2),175-186 (1992).

7. Mickey.LW and Eugene LP, Models for release of chlorpheneramine and a noninteracting compound from an inert heterogenous matrix containing an anionic surfactant, Drug development and Industrial Pharmacy, 1992, 18(3), 265-284.

8. Khan MA, and Chaturvedi SC, Swelling and Drug Release Studies from Hydrophilic Matrices Containing Combination of Different Grades of Hydroxyl Propyl Methylcellulose, Asian Journal of Chemistry, Vol. 23,Issue8(2011),3566 - 3568

9. Liberman H, Lachman L and Schwartz J, Pharmaceutical Dosage Forms: Tablets. vol.1, $2^{\text {nd }}$ edition revised and expanded, Dekker, New York, 2005. rate from a dosage form and indicates the drug release retarding efficiency of polymer.

Comparisons of the observed responses with that of the anticipated responses along with percentage error for dissolution parameters like $\mathrm{n}$ and Rel $12 \mathrm{~h}$ of optimized matrix tablets formulation shows the prognostic ability of matrix tablet formulations of Chlorpheniramine maleate using optimization method and is validated.

\section{CONCLUSION}

Chlorpheniramine maleate matrix tablets containing combination of polymers HPMCK4M and HPMCK15M, confirms excellent promises for drug release prolongation. Results of the dissolution studies for optimized formulation fulfilled maximum requisites because of better regulation of release rate. Rational use of optimization methodology helped to predict the best possible formulations and confirms the prognostic ability of optimization method. Using the traditional methods, however, the best formulation might have skipped the observations of the formulation scientist. Conclusively, the current study attained the successful design, development, optimization and formulation of chlorpheniramine maleate Tablets.

\section{ACKNOWLEDGEMENT}

Author MA Khan is grateful to Colorcon India Ltd.and Promed Labs Ltd, for providing gift drug samples.

10. Wan LSC, Heng PWS and Wong L F, Drug Dev Ind Pharm 1991; 73:111

11. Liberman H,Lachman L and Schwartz J, Pharmaceutical Dosage Forms: Tablets. vol.3, $2^{\text {nd }}$ edition revised and expanded, Dekker, New York, 2005

12. Khan M.A., and Chaturvedi S.C., Formulation of Sustained Release Zolpidem tartrate Matrix Tablets through Optimization and their Evaluation Asiaan Journal of Chemistry, Vol. 22,Issue 6(2010),47494762.

13. Rao K.V.R, and Devi K.P, Swelling controlled-release systems: recent developments and applications, Int J Pharm, 48: 1-13 (1988).

14. Efentakis M, Vlachou M, Choulis N.H, Effects of Excipients on Swelling and Drug Release from Compressed Matrices, Drug Dev. Ind. Pharm 23: 107-112 (1997).

15. Sahu LK and Sharma AK, derivative specterophotometric methods for simultaneous estimation of phenylpropanolamine, chlorpheniramine and dextromethorphan in syrups, I ndian J. Pharm. Sci., 2000(6) 427 432

16. Singh B and Singh S, A comprehensive computer program for the study of drug release kinetics from compressed matriceses, Ind. J. Pharm. Sci., 60(6), 358-362 (1998).

17. Singh B and Ahuja N, Development of Controlled-Release Buccoadhesive Hydrophilic Matrices of Diltiazem Hydrochloride: Optimization of Bioadhesion,Dissolution, and Diffusion Parameters, Drug Development and Industrial Pharmacy, 28(4):2002,431- 442.

18. Singh B and Gupta R.K., FACTOP : A Software Aid to Optimize Pharmaceutical Dosage Forms through Factorial Design in $48^{\text {th }}$ Indian Pharmaceutical Congress, Chennai. 1996, AP 63. 